\title{
Atrial fibrillation in patients with idiopathic hypertrophic subaortic stenosis
}

\author{
D. Luke Glancy, Kevin P. O'Brien'1, Herman K. Gold, and Stephen E. Epstein \\ From the Cardiology Branch, National Heart and Lung Institute, Bethesda, Maryland, U.S.A.
}

Atrial fibrillation occurred in $16(10 \%)$ of 167 patients with idiopathic hypertrophic subaortic stenosis. The clinical and haemodynamic findings in these 16 patients are presented.

Atrial fibrillation appeared late in the course of the disease, and its occurrence did not seem to be related to the severity of left ventricular outflow obstruction or to the amount of associated mitral regurgitation. In each patient the onset of the arrhythmia was accompanied by severe clinical deterioration, which often necessitated urgent medical treatment. Digitalis was administered to all I6 patients with subsequent clinical improvement in 15. Electrical cardioversion was uniformly successful in restoring sinus rhythm, but atrial fibrillation usually recurred. In each of 8 patients catheterized during atrial fibrillation, cardiac output was strikingly low (average, $\left.I \cdot 9 \mathrm{l} . / \mathrm{min} . / \mathrm{m}^{2}\right)$, whereas it was normal in 10 of 13 patients studied in sinus rhythm. The duration of follow-up from the onset of atrial fibrillation has averaged 5 years, and 3 of the I6 patients have died of causes related to their heart disease. Four have suffered cerebral emboli. Only 5 patients are now in stable sinus rhythm; in general, they are less symptomatic than the patients in whom atrial fibrillation has recurred.

The unusually severe clinical deterioration at the onset of atrial fibrillation and the low cardiac output measured during catheterization are thought to be related to the loss of the important contribution to ventricular filling of atrial systole in patients with poorly compliant ventricles, and to the effect of an irregular ventricular rhythm on the variable nature of the outflow obstruction.

Atrial fibrillation was initially believed to occur rarely in patients with idiopathic hypertrophic subaortic stenosis (Hancock and Eldridge, 1966; Lannigan, 1965; Hollister and Goodwin, 1963). As experience with this disorder grew, however, it became apparent that this disturbance in rhythm was not uncommon. In a previous review from this institution, Frank and Braunwald (1968) found that atrial fibrillation was present in 10 of 123 patients, and since then we have studied 6 additional patients with idiopathic hypertrophic subaortic stenosis and atrial fibrillation. Thus, of the 167 patients with this anomaly who have now been studied at the National Heart and Lung Institute, 16 have developed atrial fibrillation during the course of their illness, and in most of them its onset appeared to represent an ominous milestone in the course of the disease. The present investigation was undertaken in order to

Received 2 February 1970.

1 Present address: Greenlane Hospital, Auckland, New Zealand. characterize the haemodynamic findings in patients with hypertrophic stenosis and atrial fibrillation, and to determine the course of the disease once atrial fibrillation appeared.

\section{Subjects and methods}

In each patient the diagnosis was established by cardiac catheterization (Braunwald et al., 1964), and atrial fibrillation was documented electrocardiographically. In each of the patients who underwent operative treatment, the initial bout of atrial fibrillation preceded the operation. Patients whose only episode of atrial fibrillation was a transient post-operative one have been excluded from the study.

\section{Results}

A summary of the clinical information concerning the 16 patients is presented in Table $I$. The average age of the Io men and 6 women at the onset of atrial fibrillation was 40 years (range, 18 to 58 years). Paroxysmal atrial fibrillation led to the recognition of heart disease in one patient (M.K.); in each of the other 15 patients a praecordial murmur had 
TABLE I Clinical summary of patients with idiopathic hypertrophic subaortic stenosis (IHSS) and atrial fibrillation

\begin{tabular}{|c|c|c|c|c|c|c|c|c|c|}
\hline \multirow[t]{2}{*}{ Patient } & \multirow[t]{2}{*}{$\operatorname{Sex}$} & \multicolumn{2}{|l|}{ Age } & \multirow{2}{*}{$\begin{array}{l}\text { No. of } \\
\text { episodes } \\
\text { of } A F\end{array}$} & \multirow{2}{*}{$\begin{array}{l}\text { Clinical } \\
\text { deterioration } \\
\text { with } A F^{\star}\end{array}$} & \multirow{2}{*}{$\begin{array}{l}\text { No. of } \\
\text { electrical } \\
\text { cardio- } \\
\text { versions }\end{array}$} & \multirow{2}{*}{$\begin{array}{l}\text { Operation } \\
\text { for IHSS }\end{array}$} & \multirow{2}{*}{$\begin{array}{l}\text { Follow-up } \\
\text { from onset } \\
\text { of } A F \\
(y r .)\end{array}$} & \multirow[t]{2}{*}{ Current status } \\
\hline & & $\begin{array}{l}\text { When cardiac } \\
\text { disease noted }\end{array}$ & $\begin{array}{l}\text { At onset } \\
\text { of } A F\end{array}$ & & & & & & \\
\hline P.K. & $\mathbf{F}$ & 12 & 18 & Several & (Pre-S) (CHF) & 0 & 0 & 8 & Died in AF of CHF, age 26 \\
\hline M.H. & $\mathbf{F}$ & 28 & 41 & 5 & $(\mathrm{H}, \mathrm{D}$, Pre-S) & 0 & 0 & $\mathbf{I}$ & Died suddenly, age 42 \\
\hline P.S. & $\mathbf{M}$ & 9 & 20 & Many & (Pre-S) (CHF) & $\mathbf{I}$ & 0 & 13 & $\begin{array}{l}\text { Died in AF of multiple systemic } \\
\text { emboli, age } 33\end{array}$ \\
\hline J.K. & $\mathbf{M}$ & 28 & 52 & Many & $(\mathrm{S}, \mathrm{CHF})$ & 2 & 0 & 5 & $\begin{array}{l}\text { Died in AF and CHF of gastric } \\
\text { carcinoma, age } 57\end{array}$ \\
\hline R.P. & $\mathbf{M}$ & 18 & 42 & 3 & (CHF) & 2 & 0 & 5 & AF, Class III† \\
\hline R.S. & $\mathbf{M}$ & 15 & 29 & & $(\mathrm{~S}, \mathrm{D})(\mathrm{LVF})(\mathrm{A})$ & 10 & Age 3I & 4 & AF, Class II \\
\hline W.D. & $M$ & $\mathbf{2 I}$ & 44 & Many & $(\mathrm{CHF})(\mathrm{H})(\mathrm{A})$ & 10 & Age 44 & 5 & AF, Class II \\
\hline $\mathbf{W . Q}$ & $\mathbf{M}$ & 17 & 56 & Many & $(\mathrm{A}, \mathrm{D})(\mathrm{S})(\mathrm{CHF})$ & $\mathbf{I}$ & Age 59 & 4 & AF, Class III \\
\hline S.B. & $\mathbf{F}$ & 16 & 25 & & (Fa) & 5 & 0 & 4 & $\mathbf{A F}$ \\
\hline P.Sc. & $\mathbf{F}$ & 14 & 40 & Many & $(\mathrm{Fa}, \mathrm{D})$ & 0 & 0 & 7 & $\begin{array}{l}\text { Paroxysmal AF } \\
\text { Class I (NSR), Class II (AF) }\end{array}$ \\
\hline M.K. & $\mathbf{F}$ & 50 & 50 & Many & $(\mathrm{H}, \mathrm{A})(\mathrm{H}, \mathrm{C})(\mathrm{CHF})$ & 0 & 0 & 6 & $\begin{array}{l}\text { Paroxysmal AF } \\
\text { Class II (NSR), Class IV (AF) }\end{array}$ \\
\hline M.W. & $\mathbf{F}$ & 23 & 38 & $\mathbf{I}$ & $(\mathbf{H}, \mathbf{S}, \mathbf{P O e})$ & $\mathbf{I}$ & 0 & 2 & $\begin{array}{l}\text { NSR, hemiparesis due to cerebral } \\
\text { embolus }\end{array}$ \\
\hline J.L. & $\mathbf{M}$ & 29 & 42 & 2 & $(\mathrm{H}, \mathrm{A})(\mathrm{CHF})$ & $\mathbf{I}$ & Age 42 & 7 & NSR, Class II \\
\hline W.A. & $\mathbf{M}$ & 32 & 58 & 2 & (POe,CHF) & $\mathbf{I}$ & Age 58 & $\mathbf{I}$ & NSR, Class I \\
\hline D.E. & $\mathbf{M}$ & 35 & 43 & 2 & (D) & 2 & 0 & 4 & NSR, Class II \\
\hline G.E. & $\mathbf{M}$ & 35 & 47 & 3 & $(A, D)$ & 0 & 0 & 5 & NSR, Class II \\
\hline
\end{tabular}

«Those signs and symptoms which developed during the same episode(s) of AF have been enclosed together within parentheses. † Functional capacity, New York Heart Association classification. Two patients could not be classified because of mental retardation (S.B.) and hemiparesis (M.W.).

$A=$ angina $\mathbf{A F}=$ atrial fibrillation; $C=$ convulsions; $C H F=$ congestive heart failure; $D=$ dyspnoea $; \mathrm{Fa}=$ fatigue; $\mathrm{H}=$ hypotension; $\mathrm{LVF}=$ left ventricular failure; $N S R=$ normal sinus rhythm; $P O e=$ pulmonary oedema; $S=$ syncope.

been noted 6 to 39 years (average, 18 years) before the onset of atrial fibrillation. Of the I6 patients, 15 have had more than one episode of atrial fibrillation.

Three of the 16 patients were sibs (P.K., P.S., and M.W.), and 4 others had a family history of idiopathic hypertrophic subaortic stenosis. One patient (J.K.) had a family history of atrial fibrillation but no family history of hypertrophic subaortic stenosis.

Clinical deterioration with onset of atrial fibrillation All 16 patients experienced a decrease in exercise tolerance with the onset of atrial fibrillation. In addition, more striking manifestations of cardiac dysfunction (Table I) occurred with one or more episodes of atrial fibrillation in each of 13 patients: cardiac failure in II, syncope or presyncope in 7, angina pectoris in 6 , documented systemic arterial hypotension in 5, and a generalized seizure in one. In 9 of the II patients with cardiac failure, signs of both right and left ventricular failure were present. In 7 patients clinical deterioration was dramatic and required urgent treatment.

Response to treatment Each patient received digitalis, usually in combination with a diuretic drug, soon after the onset of atrial fibrillation, and distinct clinical improvement was noted after the institution of therapy in all but one patient (M.W.). She was not benefited by digitalis, vasopressors, and propranolol, and systemic arterial hypotension disappeared only after electrical cardioversion. Eight patients reverted to sinus rhythm while receiving digitalis. All, however, subsequently returned to atrial fibrillation. One (G.E.) of the 8 is now in sinus rhythm after a third reversion associated with the administration of digitalis.

Electrical cardioversion was attempted in I I patients and restored sinus rhythm in each. However, atrial fibrillation recurred from I day to 8 months later (average, 2 months) in 8 of the II, despite maintenance doses of quinidine. Six of these 8 underwent additional cardioversions; though one patient (D.E.) has remained in sinus rhythm for 4 years after a second cardioversion, atrial fibrillation soon recurred in the other 5 .

Systemic embolism Systemic emboli occurred in 4 of the 16 patients. In one (P.S.), multiple systemic emboli caused death 17 days after successful cardioversion and 15 days after cardiac catheterization. Seven days be- 

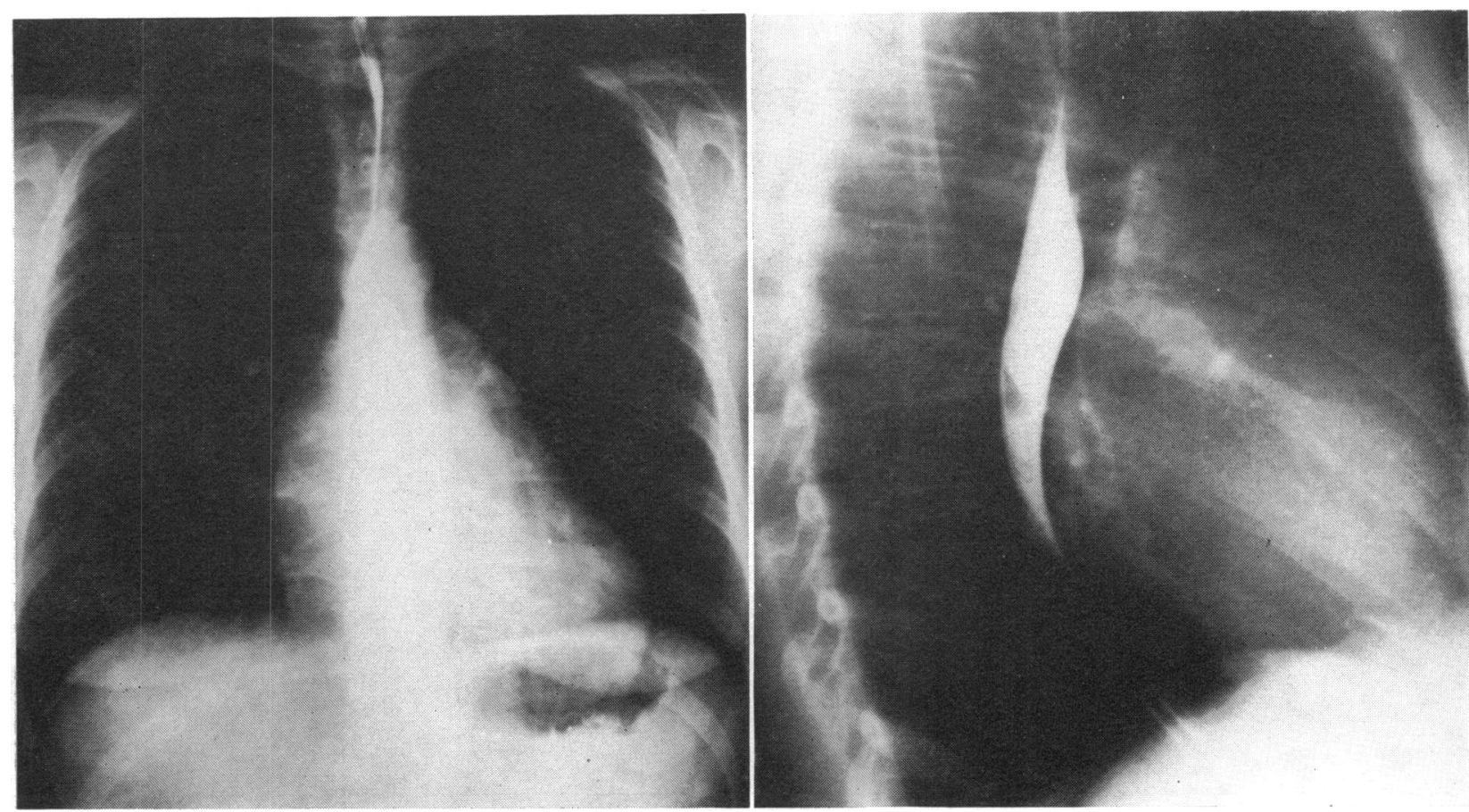

FIG. I Postero-anterior (left) and lateral (right) chest x-rays in patient M.W. Both the left atrium and the left ventricle are enlarged.

fore death atrial fibrillation had recurred, and 2 days before death this patient had suffered a major cerebrovascular accident. At necropsy an antemortem thrombus was found in the apex of the left ventricle. His sister (M.W.) experienced a cerebral embolus 4 days after the onset of atrial fibrillation and one day after electrical cardioversion. She remains limited by hemiparesis. Six years before atrial fibrillation was documented electrocardiographically, W.D. suffered a cerebral embolus, which probably occurred during a bout of paroxysmal atrial fibrillation. P.Sc. had a cerebral embolus one year after the onset of atrial fibrillation. Both of these last 2 patients made complete recoveries. During a paroxysm of atrial fibrillation one additional patient (W.Q.) developed syncope and a transient hemiparesis that may have been due to either an embolus or poor cerebral perfusion during the arrhythmia.

Radiological features The plain chest $x$ ray showed moderate to severe left atrial enlargement in 13 of the 16 patients (Fig. I). The 3 patients without left atrial enlargement had paroxysmal atrial fibrillation.

A satisfactory left ventricular angiogram was available for review in 12 patients. The angiogram showed no mitral regurgitation in 2 patients, mild regurgitation in 4 , and con- siderable regurgitation in 6 (Fig. 2). In many patients the association of mitral regurgitation, atrial fibrillation, and radiological evidence of left atrial enlargement suggested the diagnosis of rheumatic mitral valve disease.

\section{Haemodynamic data (Table 2) Eight} patients were in sinus rhythm when cardiac catheterization was performed and 3 were in atrial fibrillation. The remaining 5 patients underwent one catheterization while in sinus rhythm and another while in atrial fibrillation. In addition, in 4 of these last 5 patients haemodynamic measurements were made during both atrial fibrillation and sinus rhythm at the same catheterization.

Cardiac output was low $\left(<2.51 . / \mathrm{min} . / \mathrm{m}^{2}\right)$ in each of 8 patients studied during atrial fibrillation, whereas it was normal in 10 of 13 studied in sinus rhythm. In each of the 5 patients in atrial fibrillation during one study and in sinus rhythm during another, cardiac output was higher during sinus rhythm. Moreover, cardiac output was measured in 3 of the 4 patients who reverted from atrial fibrillation to sinus rhythm during catheterization, and in each the output was higher after reversion. In the one patient (W.D.) studied in atrial fibrillation after operation, cardiac output was lower $\left(2 \cdot 21 . / \mathrm{min} . / \mathrm{m} .{ }^{2}\right)$ than during a pre-operative study in sinus 

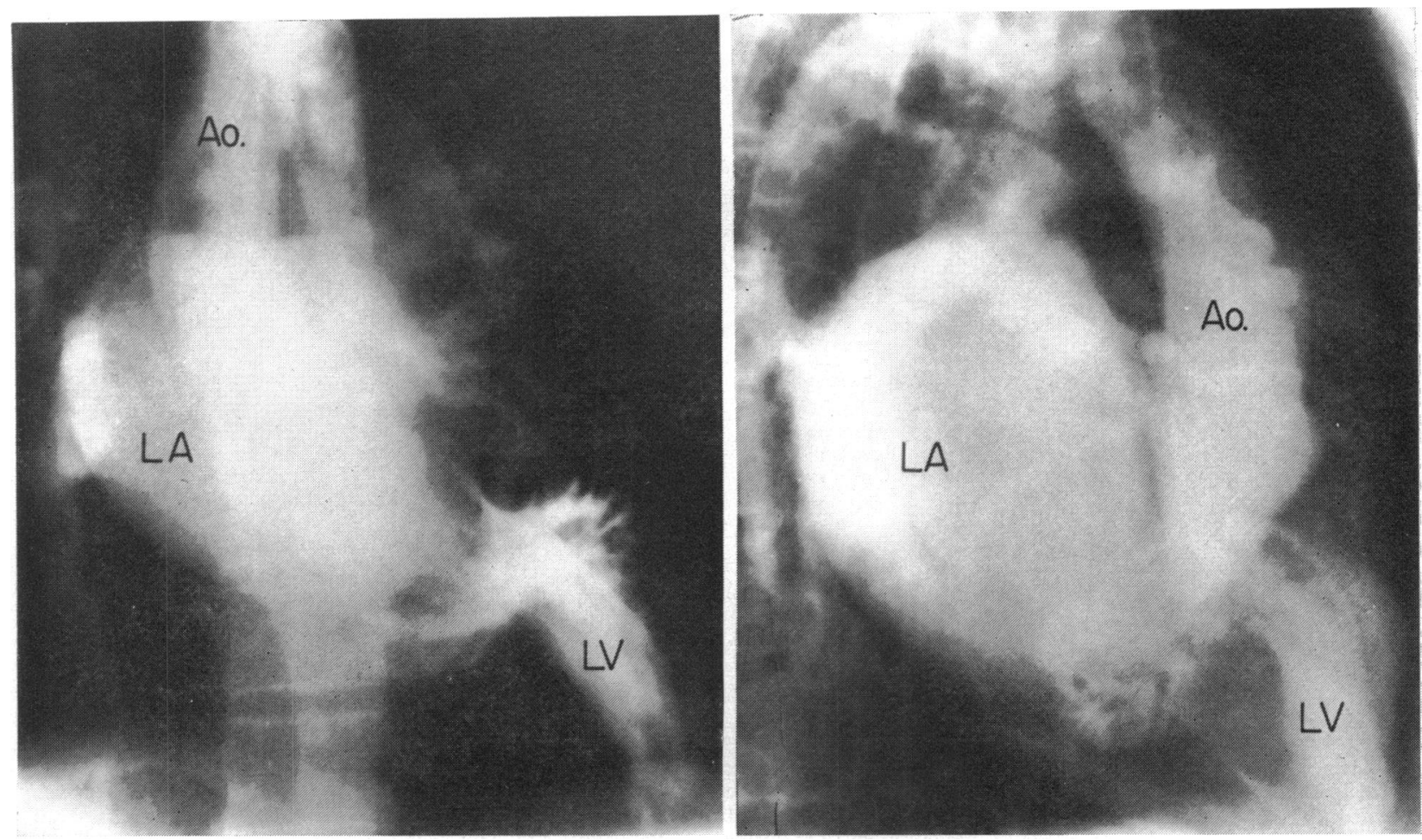

FIG. 2 Antero-posterior (left) and lateral (right) x-rays. After the injection of contrast material into the left ventricle ( $L V)$ of patient $M . W$., mitral regurgitation produces dense opacification of the large left atrium $(L A)$. The wall of the left ventricle is hypertrophied, and the configuration of its cavity is typical of idiopathic hypertrophic subaortic stenosis. The ascending aorta (Ao.) is of normal size.

rhythm, despite post-operative absence of a pressure gradient across the left ventricular outflow tract. In the 2 patients (J.L. and R.S.) studied in sinus rhythm after operation, cardiac output was normal.

Resting left ventricular outflow gradients were recorded during at least one catheterization in 15 of the 16 patients, and tended to be slightly larger in patients studied during sinus rhythm. In 5 patients, including 3 of the 4 who subsequently died, the peak systolic gradient was less than $30 \mathrm{~mm}$. Hg. Left ventricular end-diastolic pressure was abnormal ( $>\mathrm{I} 2 \mathrm{~mm} . \mathrm{Hg}$ ) on at least one occasion in all but 4 patients, 3 of whom were studied during atrial fibrillation. Though left ventricular enddiastolic pressures were on the average slightly higher in patients studied during sinus rhythm, left atrial mean pressure was approximately the same in patients with sinus rhythm as in those with atrial fibrillation. Left atrial mean pressure was abnormally high ( $>12 \mathrm{~mm} . \mathrm{Hg}$ ) in 10 of 14 patients.

Long-term clinical course The duration of follow-up from the onset of atrial fibrilla- tion has ranged from I to I3 years (average, 5 years). During the period of observation, 3 of the 16 patients died from causes related to their heart disease: one (P.S.) of multiple systemic emboli 13 years after the initial onset of atrial fibrillation; his sister (P.K.) of congestive heart failure 8 years after fibrillation began; and a third patient (M.H.) suddenly one year after the development of paroxysmal atrial fibrillation. In a fourth patient (J.K.), atrial fibrillation recurred 6 months after his second electrical cardioversion and was associated with the development of congestive heart failure, but death resulted from gastric carcinoma.

Five patients underwent left ventricular myotomy and/or myectomy (Morrow et al., I968), were cardioverted after operation, and improved clinically. Though atrial fibrillation recurred in 3 of them, in each the arrhythmia has been better tolerated than it was before operation.

Seven patients who did not undergo operation have survived. Of the 3 now in sinus rhythm, 2 are in functional Class II: one (D.E.), whose only 2 episodes of atrial fibrilla- 
TABLE 2 Haemodynamic and angiographic findings

\begin{tabular}{|c|c|c|c|c|c|c|c|c|}
\hline Patient & $\begin{array}{l}\text { Age } \\
\left(y r_{.}\right)\end{array}$ & $\begin{array}{l}\text { Cardiac } \\
\text { rhythm }\end{array}$ & $\begin{array}{l}\text { Ventricular } \\
\text { rate } \\
\text { (beats/min.) }\end{array}$ & $\begin{array}{l}\text { Resting } L V \\
\text { outflow } \\
\text { gradient } \\
(\mathrm{mm} . \mathrm{Hg})\end{array}$ & $\begin{array}{l}\text { LVEDP } \\
(\mathrm{mm} . \mathrm{Hg})\end{array}$ & $\begin{array}{l}\text { LA mean } \\
\text { pressure } \\
(\mathrm{mm} . \mathrm{Hg})\end{array}$ & $\begin{array}{l}C I \\
\left(l . / \min . / m .^{2}\right)\end{array}$ & $\begin{array}{l}\text { Mitral } \\
\text { regurgitation } \\
\text { on } L V \\
\text { angiogram }\end{array}$ \\
\hline J.L. & 42 & NSR & 79 & 133 & 26 & - & $2 \cdot 9$ & - \\
\hline M.K. & 51 & NSR & 85 & 0 & 20 & Io PAW & 3.5 & None \\
\hline P.Sc. & 43 & NSR & 78 & 53 & 14 & I5 & $2 \cdot 8$ & None \\
\hline G.E. & 49 & NSR & 70 & 20 & 12 & 6 & $3 \cdot 3$ & Mild \\
\hline W.A. & 58 & NSR & 56 & 55 & 22 & 14 & $2 \cdot 1$ & Mild \\
\hline D.E. & 37 & NSR & 60 & 90 & 15 & 20 & $2 \cdot 2$ & - \\
\hline M.W. & 32 & NSR & 90 & 55 & 25 & 12 & $2 \cdot 7$ & Considerable \\
\hline W.D. & 42 & NSR & 80 & 75 & 15 & - & $2 \cdot 7$ & Considerable \\
\hline W.Q. & 59 & $\mathrm{AF}$ & 70 & $0-75$ & 10 & 14 & $1 \cdot 6$ & Considerable \\
\hline J.K. & 56 & AF & 96 & $0-20$ & 4 & 5 & $\mathrm{I} \cdot 8$ & - \\
\hline P.K. & 25 & AF & 80 & Io & I0 & I9 & $1 \cdot 8$ & - \\
\hline \multirow[t]{2}{*}{ R.P. } & 44 & AF (NSR) & $70(69)$ & 80 & I8 & I8 (I5) & $2 \cdot 1$ & \\
\hline & 45 & NSR & 63 & 107 & 37 & 24 & $2 \cdot 8$ & Considerable \\
\hline \multirow[t]{2}{*}{ S.B. } & 19 & NSR & 105 & 70 & I2 & I5 PAW & $3 \cdot 7$ & - \\
\hline & 25 & AF (NSR) & $100(90)$ & $80(90)$ & I3 (I6) & I7 PAW & $2 \cdot I(2 \cdot 9)$ & Mild \\
\hline \multirow[t]{2}{*}{ M.H. } & 40 & NSR & 102 & 90 & 25 & I9 & $4 \%$ & Considerable \\
\hline & $4 \mathrm{I}$ & $\mathrm{AF}$ & 105 & $0-85$ & 18 & 22 & $I \cdot 8$ & - \\
\hline \multirow[t]{2}{*}{ R.S. } & 29 & AF (NSR) & $90(79)$ & $50-100(85)$ & I7（17） & 18 & $2 \cdot 2(2 \cdot 4)$ & Considerable \\
\hline & 30 & NSR & 68 & 53 & 17 & & $2 \cdot 5$ & - \\
\hline \multirow[t]{2}{*}{ P.S. } & 26 & AF (NSR) & $146(90)$ & (30) & (26) & (18) & $I \cdot 3(2 \cdot I)$ & (Mild) \\
\hline & 33 & NSR & 60 & 0 & 26 & 22 PAW & $2 \cdot 0$ & Mild \\
\hline
\end{tabular}

$A F=$ atrial fibrillation; $C I=$ cardiac index; $L A=$ left atrial $L V=$ left ventricular; $L V E D P=$ left ventricular end-diastolic pressure; $N S R=$ normal sinus rhythm; PAW = pulmonary arterial wedge pressure; ()$=$ data obtained during the same catheterization following electrical cardioversion of long-standing AF to NSR, except for patient P.S. who developed a paroxysm of AF during catheterization and who reverted with ouabain.

tion occurred in association with ureterolithotomy, has remained in sinus rhythm for 4 years after a second cardioversion; the other (G.E.) reverted from atrial fibrillation on 3 occasions after the administration of digitalis and has now been in sinus rhythm for 4 years. The third patient (M.W.) has been in sinus rhythm for 2 years after electrical cardioversion, but remains limited by hemiparesis. Two patients have paroxysms of atrial fibrillation during which they symptomatically deteriorate, and 2 are continuously in atrial fibrillation. One (R.P.) of the latter is in Class III, and in the other (S.B.) functional capacity cannot be adequately assessed because of mental retardation.

Thus, of the 9 patients with persistent atrial fibrillation, 4 have died and only 2, both of whom have had operations for idiopathic hypertrophic subaortic stenosis, are in functional Class II. In contrast, 4 of the 5 patients now in sinus rhythm are in Class I or II, and the fifth patient is limited by hemiparesis. The 2 patients with paroxysmal atrial fibrillation do well in sinus rhythm but deteriorate symptomatically with episodes of the arrhythmia. All but one patient (M.W.) are currently being treated with drugs. Each of the 5 patients in stable atrial fibrillation receives digitalis; 2 are also taking diuretics, and 3, propranolol. Among the 7 patients with sinus rhythm or paroxysmal atrial fibrillation, 4 are receiving quinidine, 3 digitalis, 3 propranolol, and I diuretics.

\section{Discussion}

The results of this investigation show that the onset of atrial fibrillation in patients with idiopathic hypertrophic subaortic stenosis is often associated with obvious clinical deterioration and an increased risk of systemic emboli. The mechanism responsible for the onset of atrial fibrillation in these patients is not clear. It does not appear to be related to the severity of left ventricular outflow obstruction, left ventricular end-diastolic pressure, or left atrial pressure. Though the majority of patients had mitral regurgitation, 2 did not. Furthermore, mitral regurgitation occurs frequently in patients with idiopathic hypertrophic subaortic stenosis and sinus rhythm (Simon, Ross, and Gault, 1967). Perhaps the best correlation can be made with left atrial size. Of the 16 patients with atrial fibrillation, 13 had moderate to severe enlargement of the left atrium. Moreover, only paroxysmal bouts of the arrhythmia occurred in patients without left atrial enlargement. Atrial fibrillation develops relatively late in the course of subaortic stenosis (average age at onset, 40 years; average duration of known heart disease, 16 
years), and therefore may also be related to progression of the basic myocardial disease. Once present, however, the arrhythmia in itself seems to cause further clinical deterioration.

The onset of atrial fibrillation leads to an increase in symptoms in patients with many types of heart disease, but the clinical deterioration observed in these patients with idiopathic hypertrophic subaortic stenosis was unusually striking. Several physiological mechanisms may have been responsible for this. First, atrial systole contributes significantly to the filling of hypertrophied and poorly compliant ventricles (Burchell, 1964; Braunwald, 1964), and the loss of atrial systole decreases stroke output on the basis of the Starling mechanism. Very low cardiac outputs were seen in the 8 patients studied during atrial fibrillation, despite left atrial mean pressures that were high in 7 of them. For left ventricular stroke volume to have been maintained, left atrial mean pressure would have had to rise even higher.

Second, atrial fibrillation causes large variations in stroke volume and thus arterial pressure. The beat following a short diastole ejects little or no blood into the aorta, resulting in a low systemic arterial pressure (Fig. 3). In patients in atrial fibrillation without left ventricular outflow obstruction or with fixed obstruction, arterial pressure is restored by the increased left ventricular stroke volume and pulse pressure that result from the long diastole that usually follows (Fig. 4, above). In patients with idiopathic hypertrophic subaortic stenosis, however, this compensatory increase in stroke volume probably does not occur. Instead, a long diastole is followed by a fall in arterial pulse pressure and a further fall in arterial systolic pressure (Fig. 4, below). The change in arterial pulse contour after a long diastole suggests that this response is caused by an increase in the degree of obstruction to left ventricular ejection. This conclusion is also suggested by studies which have shown that interventions that raise arterial pressure decrease the degree of obstruction in patients with idiopathic hypertrophic subaortic stenosis, while interventions that lower arterial pressure produce the opposite effect (Braunwald et al., 1964). The low distending pressure after a long diastole presumably causes the walls of the hypertrophied outflow tract to approximate each other more closely, and thereby increases the degree of obstruction (Lewis et al., 1965; Wigle et al., 1963). In addition, the low arterial pressure present at the end of a long diastole may cause a baroreceptor mediated increase in sympathetic stimulation to the heart, a change known to increase outflow tract obstruction in patients with idiopathic hypertrophic subaortic stenosis.

Finally, in these patients any increase in the inotropic state of the myocardium may increase left ventricular outflow obstruction. In strips of mammalian myocardium, KochWeser and Blinks (1963) have shown an increase in contractility after an early contraction (postextrasystolic potentiation), after a long interval between contractions (rest potentiation), and after a series of rapidly occurring contractions (poststimulation potentiation). Early beats, long diastolic intervals, runs of rapidly occurring beats, and various combinations of these are the hallmarks of atrial fibrillation, and indeed, Edmands, Greenspan, and Fisch (1969) have found beat-to-beat changes in ventricular inotropic state with the varying cycle lengths of atrial fibrillation. These transient increases in ventricular contractility seen in atrial fibrillation might well be accompanied by an in-

\section{FIG. 3 Simultaneous electrocardiogram} $(E C G)$ and left ventricular $(L V)$ and brachial arterial $(B A)$ pressure tracings in patient $\mathcal{Y} . K$. The cardiac rhythm is atrial fibrillation. Only a small pressure gradient is present between the left ventricle and the brachial artery on most beats. After a long diastole, however, the pressure gradient increases considerably, the brachial arterial pulse assumes the bifid configuration typical of idiopathic hypertrophic subaortic stenosis, and the pulse pressure in the brachial artery decreases. Consequently, brachial arterial pressure is not restored by the beat after a long diastole.

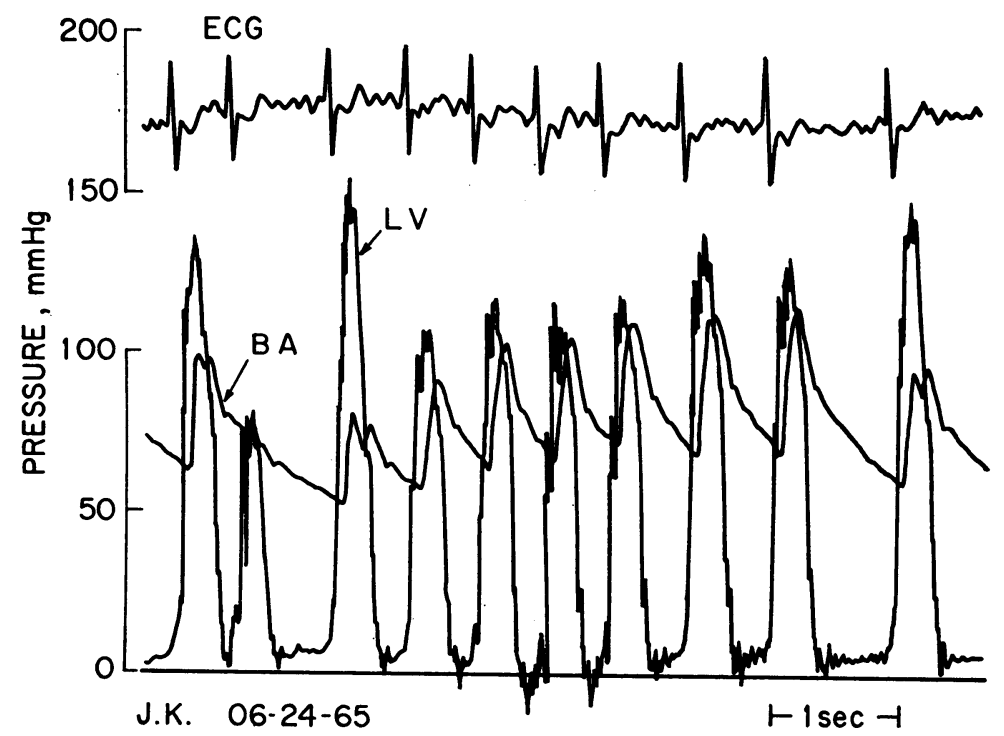


crease in left ventricular outflow obstruction in patients with idiopathic hypertrophic subaortic stenosis, and thus lead to symptomatic deterioration.

Digitalis, in combination with diuretics, resulted in symptomatic improvement in all but one of the patients with atrial fibrillation. This at first seems paradoxical, since digitalis increases the degree of obstruction in these patients in normal sinus rhythm (Braunwald et al., 1964). Such an increase in obstruction during sinus rhythm was documented after acute digitalization in the catheterization laboratory in patient P.S. When he was in atrial fibrillation, however, the administration of digitalis was associated with clinical improvement. Thus, it appears likely that the salutary effects observed in patients with idiopathic hypertrophic subaortic stenosis and atrial fibrillation after the administration of digitalis result from a slower and more regular ventricular response, rather than from an increase in myocardial contractility.

Though the onset and persistence of atrial fibrillation were associated with obvious symptomatic deterioration, the restoration of sinus rhythm was always associated with clinical improvement, and those patients able to maintain a normal rhythm have fared much better than those who returned to atrial fibrillation. Unfortunately, in most patients sinus rhythm could be restored only transiently. Atrial fibrillation recurred after the first electrical cardioversion in 8 of II patients and after additional cardioversions in 5 of 6 patients. In addition, cerebral emboli occurred soon after electrical cardioversion in 2 patients, causing death in one and permanent hemiparesis in the other.

\section{References}

Braunwald, E. (1964). Symposium on cardiac arrhythmias. Introduction, with comments on the hemodynamic significance of atrial systole. American Fournal of Medicine, 37, 665 .

—, Lambrew, C. T., Rockoff, S. D., Ross, J., Jr., and Morrow, A. G. (1964). Idiopathic hypertrophic subaortic stenosis. I. A description of the disease based upon an analysis of 64 patients. Circulation, 29 and 30, Suppl. 4, p. 3.

Burchell, H. B. (1964). A clinical appraisal of atrial transport function. Lancet, $\mathbf{I}, 775$.

Edmands, R. E., Greenspan, K., and Fisch, C. (1969). Ventricular function in atrial fibrillation: A variable inotropic state. (Abstract.) American fournal of Cardiology, 23, I 10.

Frank, S., and Braunwald, E. (1968). Idiopathic hypertrophic subaortic stenosis. Clinical analysis of 126 patients with emphasis on the natural history. Circulation, 37, 759.

Hancock, E. W., and Eldridge, F. (1966). Muscular subaortic stenosis: Reversibility with varying cardiac cycle length. American fournal of Cardiology, 18, 515 .
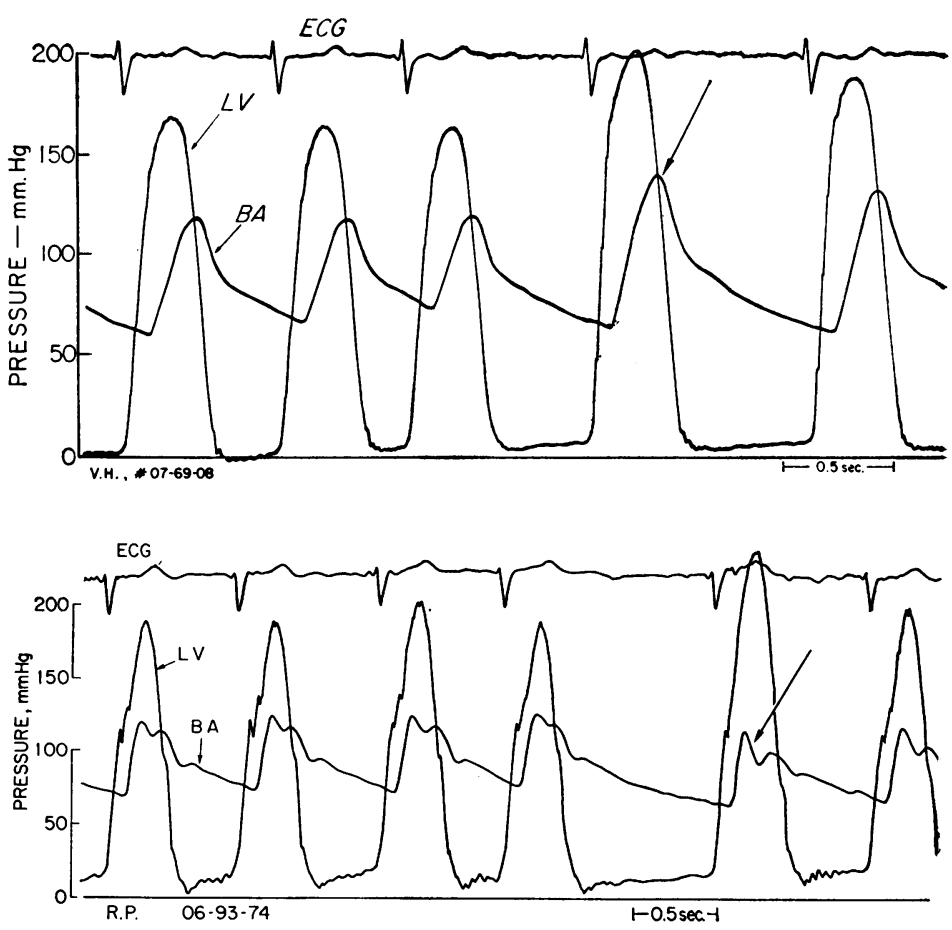

FIG. 4 Simultaneous electrocardiogram $(E C G)$ and left ventricular ( $L V)$ and brachial arterial $(B A)$ pressure tracings in patient V.H. with valvular aortic stenosis (above) and in patient R.P. with idiopathic hypertrophic subaortic stenosis (below). Both patients have atrial fibrillation. In the patient with valvular stenosis brachial arterial pulse and systolic pressures increase after a long diastole (arrow) despite a slight increase in the systolic pressure gradient between the left ventricle and brachial artery. In contrast, in the patient with idiopathic hypertrophic subaortic stenosis brachial arterial pulse pressure does not increase after a long diastole (arrow), and the systolic pressure falls. In addition, after a long diastole a large pressure gradient develops between the left ventricle and brachial artery, and the brachial arterial pulse becomes more bifid.

Hollister, R. M., and Goodwin, J. F. (1963). The electrocardiogram in cardiomyopathy. British Heart Fournal, 25, 357.

Koch-Weser, J., and Blinks, J. R. (1963). The influence of the interval between beats on myocardial contractility. Pharmacological Reviews, 15, 601.

Lannigan, R. (1965). Hypertrophic subaortic stenosis with myocardial fibre degeneration. British Heart fournal, 27, 772.

Lewis, R. P., Bristow, J. D., Farrehi, C., Kloster, F. E., and Griswold, H. E. (1965). Idiopathic left ventricular hypertrophy. A hemodynamic reappraisal. American fournal of Medicine, 38, 842.

Morrow, A. G., Fogarty, T. J., Hannah, H., III, and Braunwald, E. (1968). Operative treatment in idio- 
pathic hypertrophic subaortic stenosis: Techniques, and the results of preoperative and postoperative clinical and hemodynamic assessments. Circulation, $37,589$.

Simon, A. L., Ross, J., Jr., and Gault, J. H. (1967). Angiographic anatomy of the left ventricle and mitral valve in idiopathic hypertrophic subaortic stenosis. Circulation, 36, 852.

Wigle, E. D., Lenkei, S. C. M., Chrysohou, A., and Wilson, D. R. (1963). Muscular subaortic stenosis: Effect of peripheral vasodilatation. Canadian Medical Association fournal, 89, 896.

\section{Addendum}

Since this manuscript was prepared, we have studied two additional men with idiopathic hyper- trophic subaortic stenosis and atrial fibrillation. In J. G. fibrillation began at age $\equiv 7$ and at first was paroxysmal, but 5 years later (and 2 years after left ventricular myectomy) persistent atrial fibrillation occurred. R. M. developed persistent fibrillation at age 45 . Both patients deteriorated clinically with the onset of atrial fibrillation. Digitalis and diuretics improved both of them, but in R. M. heart rate and symptoms were better controlled when propranolol also was given. Electrical cardioversion restored sinus rhythm in each patient, but J. G. has undergone a second cardioversion because, despite quinidine therapy, atrial fibrillation recurred 2 months later. Four hours after cardioversion R. M. suffered a large pulmonary embolus: he gradually recovered. 